\title{
THE EFFECTS OF GENERAL ANAESTHESIA ON THE SURFACE TENSION OF SECRETIONS IN THE UPPER AIRWAY IN PATIENTS WITH AND WITHOUT PULMONARY DISEASE
}

\author{
Theodore H. Stanley, M.D. * And Bashir A. Zikria, M.D., F.A.C.s. $†$
}

IT HAS BEEN SUGGESTED that the surface tension of upper airway secretions may reflect alveolar surfactant activity and so may be a simple way of measuring the tendency of alveoli to collapse. ${ }^{1,2}$ Recent work has confirmed that these secretions contain surfactant metabolites ${ }^{1}$ and possess significant surface activity. ${ }^{2}$ This activity, like that possessed by distal alveolar surfactant, is decreased by fat soluble inhalation anaesthetics. ${ }^{3}$ Patients with chronic lung disease or a history of smoking also have less alveolar surfactant activity, ${ }^{4}$ which should be reflected by higher surface tensions in their upper airway secretions. Fat soluble inhalation anaesthetics may further depress surfactant activity in these patients. This study was conducted to compare the surface tensions of upper airway secretions in patients with and without pulmonary disease and to determine the effects of a fat soluble and of a fat insoluble inhalation anaesthetic on these values.

\section{METHODS}

The surface activity of the bronchial secretions of 37 patients selected at random was analysed before and after the administration of one of two inhalation anaesthetics. Informed consent was obtained from each patient at the time of the preanaesthetic visit. All patients were A.S.A. class I, II or III and scheduled for an elective orthopaedic, gynaecological or general surgical operation. Fourteen were considered to have significant chronic pulmonary disease. They either smoked 1.5 packages or more of cigarettes per day, had an obstructive defect on pulmonary function testing or were known to have bronchitis or emphysema. The rest of the patients were non-smokers with normal pulmonary function studies and no history of pulmonary disease.

Premedication included a barbiturate (1-2 $\mathrm{mg} / \mathrm{kg}$ ) and atropine or scopolamine $(0.05-0.1 \mathrm{mg} / \mathrm{kg})$ one and one-half hours before the scheduled time of operation. Each patient was allowed to breathe oxygen for five minutes before induction. Tracheal intubation was accomplished with the use of a sleep dose of sodium thiopentone ( 3 to $5 \mathrm{mg} / \mathrm{kg}$ ) given intravenously. After the tracheal tube had been secured and the cuff inflated, $5 \mathrm{ml}$ of sterile saline was instilled through the tracheal tube and the patient's lungs were ventilated with 100 per cent oxygen for one

From the Departments of Anesthesiology and Surgery, The Colombia-Presbyterian Medical Center, 622 W. 168th St., New York, N.Y. 10032

"Fellow in Anesthesiology. Present Address: Division of Anesthesiology, The University of Utah Medical Center, 50 North Medical Drive, Salt Lake City, Utah 84112.

† Assistant Professor of Surgery and Assistant Attending Surgeon. 
TABLE I

Minimal Surface Tension Changes After Nitrous Oxide Plus Narcotics

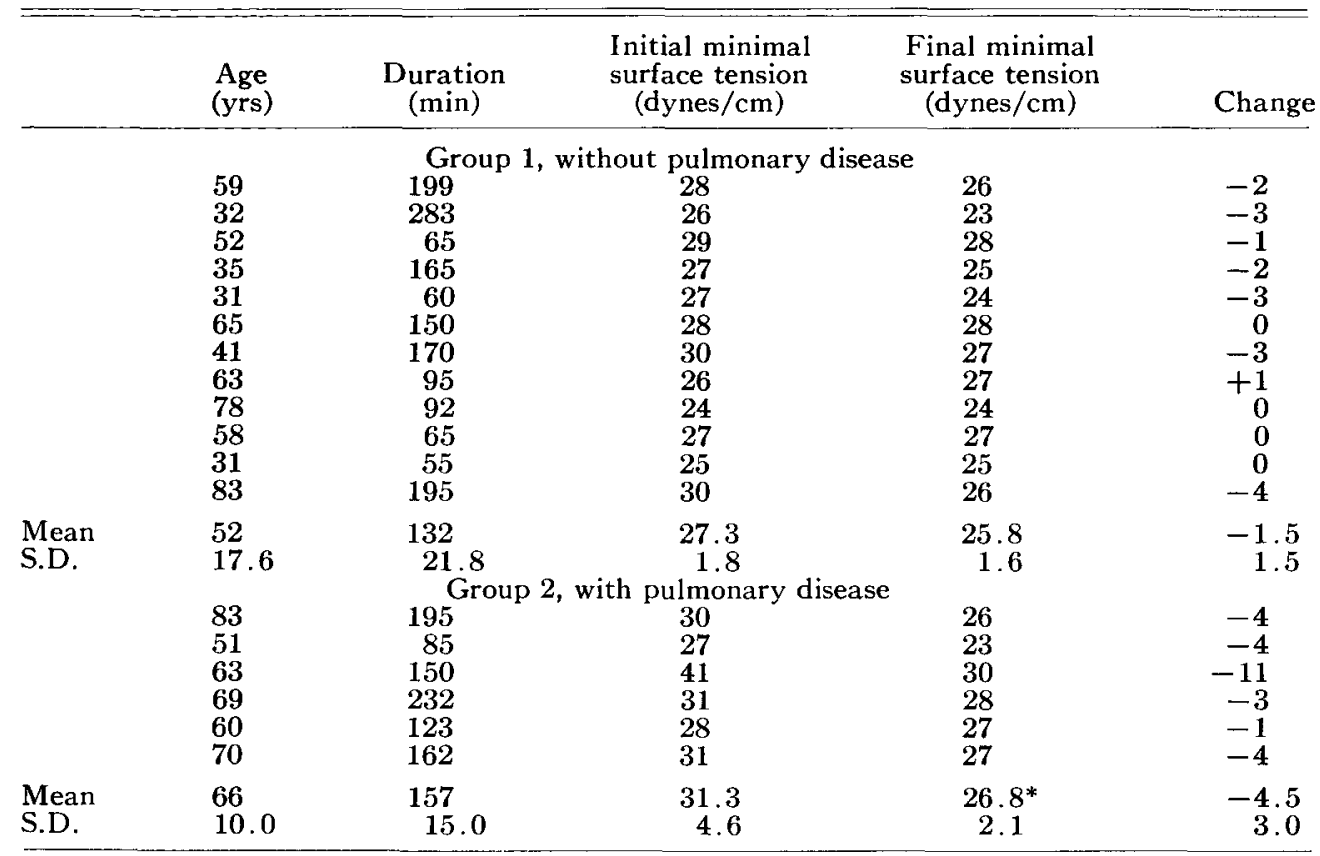

$* \mathrm{P}<.001$, students t-test.

minute. A sterile \#16 Fr. suction catheter was then introduced into the tracheal tube and advanced to the origin of the main stem bronchi. Both bronchi and the trachea were suctioned for a period of five seconds. Usually 0.5 to $1.0 \mathrm{ml}$ of material was aspirated and these secretions were captured in a Lukens specimen collector. In three patients less than $0.5 \mathrm{ml}$ was obtained on the initial aspiration and the process was then repeated. Following this collection of secretion sterile saline was added to the Lukens tube to make a total volume of $2 \mathrm{ml}$ and the sample was quickly frozen until analyzed. After this initial sample had been obtained, the inhalation anaesthetics were started and the surgical procedure was begun. Each patient received either nitrous oxide ( 60 to 70 per cent) + oxygen ( 30 to 40 per cent) + intravenous morphine ( 10 to $30 \mathrm{mg}$ ) or meperidine ( 75 to $350 \mathrm{mg}$ ) (Table I); or halothane ( 0.5 to 2.0 per cent $)+$ nitrous oxide ( 60 per cent $)+$ oxygen ( 40 per cent) Table II. The patients were further divided into two groups. Groups I and III were normal (PN) and groups II and IV had pulmonary disease (PD).

The lungs of all patients were mechanically ventilated at rates of 8 to 14 breaths per minute and with volumes of 8 to $14 \mathrm{ml} / \mathrm{kg}$ as measured by a Wright spirometer incorporated in the circle system. In this manner arterial $\mathrm{P}_{\left({ }^{\prime}\right)_{2}}$ was maintained between 32 and 38 torr as determined from radial artery blood samples at 30 minute intervals. A total of ten anaesthesiologists gave the anaesthetics for the 37 patients. 
TABLE II

Minimal Surface Tension Changes After Halothane

\begin{tabular}{|c|c|c|c|c|c|}
\hline & $\begin{array}{c}\text { Age } \\
\text { (yrs) }\end{array}$ & $\underset{(\min )}{\text { Duration }}$ & $\begin{array}{l}\text { Initial minimal } \\
\text { surface tension } \\
\quad(\text { dynes } / \mathrm{cm})\end{array}$ & $\begin{array}{l}\text { Final minimal } \\
\text { surface tension } \\
(\text { dynes } / \mathrm{cm})\end{array}$ & Change \\
\hline & $\begin{array}{l}66 \\
49 \\
43 \\
74 \\
75 \\
77 \\
52 \\
61 \\
33 \\
29 \\
41\end{array}$ & $\begin{array}{l}\text { Group } \\
105 \\
235 \\
55 \\
65 \\
215 \\
105 \\
50 \\
142 \\
170 \\
162 \\
130\end{array}$ & $\begin{array}{c}\text { hout pulmonary } \\
31 \\
23 \\
26 \\
28 \\
27 \\
27 \\
26 \\
25 \\
29 \\
28 \\
27\end{array}$ & $\begin{array}{c}\text { se } \quad 33 \\
28 \\
29 \\
35 \\
33 \\
31 \\
30 \\
34 \\
35 \\
31 \\
34\end{array}$ & $\begin{array}{l}+2 \\
+5 \\
+3 \\
+7 \\
+5 \\
+4 \\
+4 \\
+9 \\
+6 \\
+3 \\
+7\end{array}$ \\
\hline $\begin{array}{l}\text { Mean } \\
\text { S.D. }\end{array}$ & $\begin{array}{l}54 \\
16.4 \\
62 \\
46 \\
40 \\
51 \\
61 \\
83 \\
55 \\
69\end{array}$ & $\begin{array}{c}130 \\
18.7 \\
\text { Grou } \\
240 \\
290 \\
105 \\
90 \\
142 \\
195 \\
292 \\
84\end{array}$ & $\begin{array}{c}27.0 \\
2.0 \\
\text { ith pulmonary di } \\
24 \\
30 \\
31 \\
29 \\
25 \\
32 \\
30 \\
31\end{array}$ & $\begin{array}{l}32.1^{*} \\
2.3 \\
27 \\
23 \\
32 \\
30 \\
34 \\
32 \\
30 \\
29\end{array}$ & $\begin{array}{r}5.1 \\
2.0 \\
+3 \\
+7 \\
+1 \\
+1 \\
+9 \\
+0 \\
0 \\
-2\end{array}$ \\
\hline $\begin{array}{l}\text { Mean } \\
\text { S.D. }\end{array}$ & $\begin{array}{l}58 \\
12.7\end{array}$ & $\begin{array}{r}179 \\
25.7\end{array}$ & $\begin{array}{r}29.0 \\
2.7\end{array}$ & $\begin{array}{r}29.6 \\
3.1\end{array}$ & $\begin{array}{l}0.6 \\
4.2\end{array}$ \\
\hline
\end{tabular}

${ }^{*} \mathrm{P}<.001$, students t-test.

None of them had any further connection with the study. As the operation was nearing completion and before the anaesthetic gases were turned off, a second and final tracheo-bronchial sample was obtained as described above and also quickly frozen.

The samples were analyzed on a standard Kimray ${ }^{*}$ pneumatic surfactometer initially described by Greenfield and Kimmell..$^{5}$ This instrument is basically a modified Langmuir-Wilhelmy balance in which a platinum strip subtends the surface of the sampling fluid. Changes in vertical pull (surface tension) on the platinum strip are measured as surface area is changed by a moving barrier and are recorded by a pneumatic sensor and amplification system.

The frozen samples were allowed to thaw and additional saline was added to give a volume of $50 \mathrm{ml}$. The solution was then mixed with a magnetic stirrer and filtered through cotton gauze into the teflon trough of the surfactometer. After 60 minutes of aging in a glass encasement to allow the migration of surface active materials to the surface, compression and expansion cycles were begun. The area of surface film for each sample was repeatedly compressed and re-expanded until a stable replication of the hysteresis loop was obtained during a two-hour period. The point of minimal surface tension ( $\gamma$ min) being a sensitive index of surface activity in solutions containing surfactant, was recorded for each sample.

${ }^{*}$ Kimray, Inc., 52 N.W. 42nd St., Oklahoma City, Okla. 


\section{Results}

Eighteen of the 37 patients received nitrous oxide supplemented with narcotics ( 12 without and six with pulmonary disease, groups I and II) and 19 received halothane ( 11 without and eight with pulmonary disease, groups III and IV). The four groups were similar with respect to the ages of the patients and duration of the operations, using the rank and sum test at the 1 per cent level.

Preinhalation anaesthetic $\gamma$ min (minimal surface tension) values for all patients ranged from $23-41$ dynes $/ \mathrm{cm}$. The initial mean $\gamma$ min of the $23 \mathrm{PN}$ patients (groups I and III) was 27.1 dynes/cm while that of the 14 PD patients (groups II and IV) was 30.0 dynes $/ \mathrm{cm}$. This difference was statistically significant when examined with Student's t-test, $(\mathbf{P}<0.02)$.

Post-anaesthetic $\gamma$ mins for all patients ranged from 23-35 dynes/cm. When considered without regard to the anaesthetic they had received neither the $23 \mathrm{PN}$ patients nor the 14 with PD experienced significant changes in their secretion $\gamma$ mins after anaesthesia.

Halothane resulted in a mean increase in $\gamma$ min of 5.1 dynes $/ \mathrm{cm}$ in $\mathrm{PN}$ patients (group III). This change was very significant, $(\mathrm{P}<0.001$ ) but there was no correlation of duration of anaesthesia with change in surface tension. Halothane did not affect the already elevated $\gamma$ mins of those with PD (group IV).

While PN patients receiving nitrous oxide plus narcotics (group I) did not have a significant change in their $\gamma$ min values after anaesthesia, those with PD (group II) and already elevated $\gamma$ mins sustained an average decrease in their $\gamma$ min of 4.5 dynes/cm after this anaesthetic. This change was very significant $(P<0.001)$ but there was no correlation of duration of anaesthesia with change in surface tension.

\section{Discussion}

Pulmonary surfactant, a complex mixture of phospholipids, neutral lipids and polysaccharides produced by alveolar type II pneumocytes, is vital for the maintenance of alveolar stability. ${ }^{6}$ Its deficiency in respiratory distress of the newborn, ${ }^{7-9}$ many types of acute ${ }^{10}$ and chronic lung disease ${ }^{4}$ and after pulmonary fat embolism, ${ }^{11}$ prolonged cardiopulmonary bypass ${ }^{12}$ and hyperbaric oxygen breathing $^{13}$ is one of the explanations for the decreased pulmonary compliance, increased atelectasis and pulmonary shunting characteristic of these conditions. Fat soluble inhalation anaesthetics have also been shown to decrease surfactant activity. ${ }^{14,15}$ However, the significance of these effects in anaesthetized man has not been determined. One reason for this is that no safe, clinically applicable method of obtaining alveolar surfactant for surface activity measurements is available. Current methods of measuring pulmonary surface tension require either an extract from a lung biopsy or material from lung washings. Since the former method necessitates an open thoracotomy and the latter frequently increases surface tension in the lungs from which the washings have been obtained, neither can be used in standard clinical practice. Gluck et al. ${ }^{1}$ suggested that a simple solution to this dilemma might be the use of the surface tension of upper airway secretion as a mirror of alveolar surfactant activity. They found that these secretions contain 
phospholipids similar to those considered to be part of the alveolar surfactant complex. Previous work from this laboratory has shown that upper airway secretions can be aspirated easily and safely, and possess significant surface tension reducing properties. Their $\gamma$ min values are stable, reproducible and increase like alveolar surfactant on exposure to fat soluble inhalation anaesthetics. ${ }^{2,3}$

These experiments demonstrate that patients with chronic lung disease or with a history of smoking have less surface activity in their upper airway secretions than normal. This confirms work by Cook and Webb, ${ }^{4}$ who found decreased levels of alveolar surfactant in a similar group of patients and suggested that the cellular debris and purulent material associated with these conditions inactivates, destroys or alters surfactant. They also found that surface activity could be increased in these patients by encouraging them to cough and clean out the tracheobronchial tree. Controlled positive pressure ventilation also promotes drainage and clearing of the tracheobronchial tree ${ }^{16}$ and is probably the reason why group II patients had such marked increases in surface activity of their secretions after anaesthesia. These patients had received nitrous oxide, a gas insoluble in fat (fat/blood solubility of 2.3$)^{1 \tau}$ which should not alter surfactant activity. ${ }^{15}$ PD patients receiving halothane (group IV), an anaesthetic highly soluble in fat (fat/blood solubility of 60$)^{17}$ which does inactivate surfactant, ${ }^{14,15}$ did not experience a significant change in post-anaesthetic $\gamma$ min values. On the other hand halothane significantly elevated post-anaesthetic $\gamma$ mins in PN patients (group III). These findings suggest that positive pressure ventilation can increase secretion surface activity in PD patients but that the concomitant use of a fat soluble inhalation anaesthetic with its inactivating effects on surface active materials overcomes the benefits of such therapy.

Whether the changes shown in these experiments to affect the surface tension of secretions also occur at the alveolar level and so result in clinically significant changes in atelectasis and pulmonary shunting has still to be determined. If they do, it would suggest that fat soluble inhalation anaesthetics should be avoided in patients with known decreases in pulmonary surfactant. In addition and perhaps more important, it would document the validity of surface tension of upper airway secretion as a mirror of surfactant activity and provide us with a valuable method of evaluating alveolar function.

\section{SUMmary}

The surface activity of tracheal-bronchial secretions of 37 patients with and without chronic pulmonary disease were measured before and during inhalation anaesthesia. Patients with pulmonary disease (PD) had significantly higher mean minimal surface tensions of secretions ( $\gamma$ mins $)$ before anaesthesia than those without disease (PN). Halothane, a fat soluble anaesthetic, significantly elevated secretion $\gamma$ mins in PN patients but did not affect those with PD. Nitrous oxide, a gas not soluble in fat, did not change secretion $\gamma$ mins in PN patients but significantly decreased these values in those with PD. These findings suggest that positive pressure ventilation can increase surfactant activity in patients with pulmonary disease but concomitant use of a fat soluble inhalation anaesthetic may overcome the benefits of such therapy. 


\section{RÉSUMÉ}

Les malades porteurs de maladies pulmonaires (M.P.) présentent, dans les sécrétions de leurs voies respiratoires hautes, une tension de surface moyenne minimale ( $\gamma$ mins) plus élévée que les malades normaux (M.N.) Une substance anesthésique soluble dans les graisses tel l'halothane élève de façon significative la $\gamma$ mins chez les $M N$ mais ne change rien chez les MP. Le protoxyde d'azote, un gaz insoluble dans les graisses, diminue de façon significative la $\gamma$ mins des sécrétions chez les porteurs MP et n'affecte pas la $\gamma$ mins des sécrétions des MN. Ces découvertes permettent de croire que la ventilation avec pression positive peut accroître l'activité du surfactant chez les porteurs de maladies pulmonaires mais que l'usage concomittant d'un agent anesthésique par inhalation et soluble dans les graisses peut entraver les effets bénéfiques de cette thérapie.

\section{REFERENCES}

1. Gluck, L., Lulovich, M.V., Motoyama, E.K., Smits, H.L., Emelman, A., Khazin, A., \& Cook, C.D. Biochemical basis for the respiratory distress syndrome. 77th Ann. Meeting. Amer. Ped. Soc., 1967.

2. Stanley, T.H., Zikria, B.A., \& Sullivan, S.F. The surface tension of tracheobronchial secretions during general anesthesia. Anesthesiology, 37: 445 (1972).

3. Stanley, T.H. \& Zikria, B.A. The effects of fat soluble anesthetics on tracheal-bronchial secretion surface tension. Surgery, 73: 386 (1973).

4. Cook, W.A. \& WebB, W.R. Surfactant in chronic smokers. Ann. Thor. Surg., $3: 327$ (1966).

5. Greenfield, L.F. \& Kimmeld, G.O. Application of pneumatic techniques to surface tension determinations: The surfactometer. J. Surg. Res., $7: 276$ ( 1967 ).

6. Scarpelli, E.M. The surfactant system of the lung, 1st Ed., Philadelphia, Lea and Febiger (1968).

7. Avery, M.E. \& MEad, J. Surface properties in relation to atelectasis and hyaline membrane disease. Amer. J. Dis. Child, $97: 517$ (1959).

8. Gruenwald, P. Surface tension as a factor in the resistance of neonatal lungs to aeration. Amer. J. Obs. Gyn., 53: 996 (1947).

9. Pattle, R.E. Properties, function, and origin of the alveolar lining layer. Proc. Roy. Soc. (London), B148: 217 (1958).

10. Sutnick, A.I. \& Soloff, L.A. Atelectasis with pneumonia. Ann. Int. Med., 60: 39 ( 1964 ).

11. Hamilton, R.W., Jr., Hustead, R.F., \& Peltier, L.F. Fat embolism: the effect of particulate embolism on lung surfactant. Surgery 56: 53 (1964).

12. Gardnen, R.E., Finley, T.N., \& Tooley, W.H. The effect of cardiopulmonary bypass on surface activity of lung extracts. Bull. Soc. Int. Chir., 21: 542 ( 1962 ).

13. Webi, W.R., Lanius, J.W., Aslam, A., \& Reynolds, R.C. The effects of hyperbaric oxygen tensions on pulmonary surfactant in guinea pigs and rats. J.A.M.A., 195: 279 (1966).

14. Motoyama, E.K., Gluck, L., Kiknowa, Y., Kulovick, M.V., \& Suzuki, Y.O. The effects of inhalation anesthetics on pulmonary surfactant. Anesthesiology 30:347 (1969).

15. Woo, S.W., Berlin, D., \& Hedley-Whyte, J. Surfactant function and anesthetic agents. J. Appl. Physiol. 26: 571 (1969).

16. Bendixen, H.H., Egbert, L.D., Hedley-White, J., Laver, M.B., \& Pontoppidan, H. Respiratory care. 1st Ed., Saint Louis: Mosby, Chapter 9 ( 1965 ).

17. Collins, V.J. Principles of anesthesiology, 1st ed., Philadelphia, Lea and Febiger, pp. 215 (1966). 